\title{
Analytical and Experimental Investigation About Heat Transfer of Hot-Wire Anemometry
}

\author{
Mojtaba Dehghan Manshadi and Mohammad Kazemi Esfeh
}

Additional information is available at the end of the chapter

http://dx.doi.org/10.5772/51989

\section{Introduction}

The hot-wire anemometer is a famous thermal instrument for turbulence measurements [1]. The principle of operation of the anemometer is based on the heat transfer from a fine filament where it is exposed to an unknown flow that varies with deviation in the flow rate. The hot-wire filament is made from a special material that processes a temperature coefficient of resistance [2]. Thermal anemometry is the most common method employed to measure instantaneous fluid velocity. It may be operated in one of these two modes, constant current (CC) mode and constant temperature (CT) mode.

Constant-Current (CC) mode: In this mode, the current flow through the hot wire is kept constant and variation in the wire resistance caused by the fluid flow is measured by monitoring the voltage drop variations across the filament.

Constant Temperature (CT) mode: In this mode, the hotwire filament is positioned in a feedback circuit and tends to maintain the hotwire at a constant resistance and hence at a constant temperature and fluctuations in the cooling of the hot wire, filaments are similar to variations in the current flow through the hotwire.

Hot wire anemometers are normally operated in the constant (CTA) mode. The hot-wire anemometry has been used for many years in fluid mechanics as a relatively economical and effective method of measuring the flow velocity and turbulence. It is based on the convective heat transfer from a heated sensing element .Briefly; any fluid velocity change would cause a corresponding change of the convective heat loss to the surrounding fluid from an electrically heated sensing probe. The variation of heat loss from the thermal element can be interpreted as a measure of the fluid velocity changes. In subsonic incompressible flow the heat transfer from a hot wire sensor is dependent on the mass flow, ambient temperature and wire temperature. Since density variations are assumed to be zero, 
the mass flow variations are only function of velocity changes. The major advantage of maintaining the hot wire at a constant operational temperature and thereby at a constant resistance is that the thermal inertia of the sensing element is automatically adjusted when the flow conditions are varied. The electronic circuit of chosen CTA is shown schematically in Fig. 1. This mode of operation is achieved by incorporating a feedback differential amplifier into the hot-wire anemometer circuit. Such set-up obtains a rapid variation in the heating current and compensates for instantaneous changes in the flow velocity [2]. The sensing element in case studied in this research is a tungsten wire that is heated by an electric current to a temperature of approximately $250{ }^{\circ} \mathrm{C}$. The heat is transferred from the wire mainly through convection. This heat loss is strongly dependent on the excess temperature of the wire, the physical properties of the sensing element and its geometrical configuration. The authors strive to present an analytical solution for heat transfer equation of hotwire for states that can ignore the radiation term for the wire. The fundamental principle of hot-wire anemometer is based on the convective heat transfer, thus in the research, an attempt is made to develop a better perception from the heat transfer of the hotwire sensor. Also, the effect of air flow temperature variations on the voltage of hot wire, CTA has been studied experimentally. Furthermore, on the basis of air flow velocity and ambient temperature variations, the percentage errors in velocity measurements have been calculated. Finally, based on results, an accurate method has been proposed to compensate for air flow temperature variations.

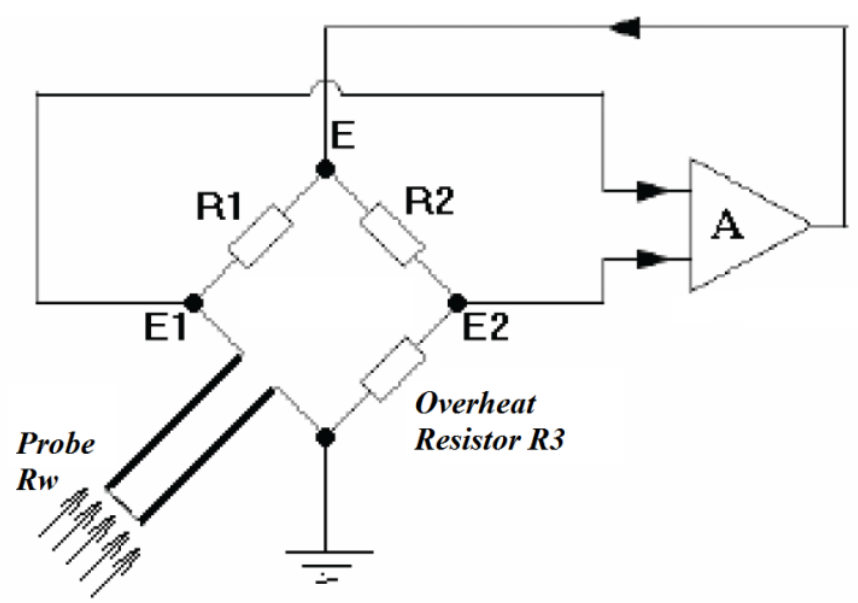

Figure 1. Schematic of a constant temperature anemometer

\section{Theoretical background}

The hot-wire involves one part of a Wheatstone bridge, where the wire resistance is kept constant over the bandwidth of the feedback loop. The electrical power dissipation $\dot{Q}_{\text {elec }}$ when the sensor is heated, is given by: 


$$
\dot{Q}_{\text {elec }}=I^{2} R_{w}
$$

I and $R_{w}$ are the current passing through the sensor and the resistance of the sensor at the temperature $\mathrm{Tw}$, respectively. The convection heat transfer rate to the fluid can be expressed in terms of the heat-transfer coefficient $h$, as:

$$
\dot{\mathrm{Q}}=\mathrm{A}_{w} \mathrm{~h}\left(\mathrm{~T}_{\mathrm{W}}-\mathrm{T}_{\mathrm{a}}\right)
$$

Where $A_{w}$ is the surface area of sensor and $\left(T_{w}-T_{a}\right)$ is the difference between the temperature of the hot-wire sensor and the temperature of the fluid. For steady-state operation, the rate of electric power dissipation equals to the rate of convective heat transfer (assuming the conductive heat transfer to the two prongs is negligible). Thus,

$$
\mathrm{I}^{2} \mathrm{R}_{\mathrm{W}}=\pi \mathrm{dLh}\left(\mathrm{T}_{\mathrm{W}}-\mathrm{T}_{\mathrm{a}}\right)=\pi \mathrm{Lk}\left(\mathrm{T}_{\mathrm{W}}-\mathrm{T}_{\mathrm{a}}\right) \mathrm{Nu}
$$

By introducing the wire voltage $E_{w}=I_{w}$ and using equation (3), one can conclude that ( $k$ is the thermal conductivity of the fluid):

$$
\frac{\mathrm{E}_{\mathrm{W}}^{2}}{\mathrm{R}_{\mathrm{W}}}=\pi \mathrm{Lk}\left(\mathrm{T}_{\mathrm{W}}-\mathrm{T}_{\mathrm{a}}\right) \mathrm{Nu}
$$

According to the pioneering experimental and theoretical work by King, the convective heat transfer is often expressed in the following form:

$$
\mathrm{Nu}=\mathrm{A}+\mathrm{BRe}^{\mathrm{n}}
$$

Where $\mathrm{A}$ and $\mathrm{B}$ are empirical calibration constants. For long wires in air, King found that $\mathrm{A}=0.338, \mathrm{~B}=0.69$ and $\mathrm{n}=0.5$. It is interesting to note that King based his derivations on the assumption of potential flow, which is a poor approximation of the real flow around a wire at low Reynolds' numbers, so King's derivation is in a sense approximately erroneous. Nevertheless, King's law has been the considered tool for fitting calibration data in practical hot-wire anemometry for almost a hundred years [3].

By introducing equation (5) into equation (4) can give:

$$
\frac{\mathrm{E}_{\mathrm{W}}^{2}}{\mathrm{R}_{\mathrm{W}}}=\pi \mathrm{Lk}\left(\mathrm{T}_{\mathrm{W}}-\mathrm{T}_{\mathrm{a}}\right)\left(\mathrm{A}+\mathrm{B}\left(\frac{\rho \mathrm{d}}{\mu}\right)^{0.5} \mathrm{U}^{0.5}\right)
$$

Equation (6) states that the hot-wire voltage is sensitive both to the velocity and temperature of air. Here, rearranging the equation (6) gives:

$$
\frac{\mathrm{E}_{\mathrm{W}}^{2}}{\mathrm{R}_{\mathrm{W}}}=\left(\mathrm{A}+\mathrm{BU}^{0.5}\right)\left(\mathrm{T}_{\mathrm{w}}-\mathrm{T}_{\mathrm{a}}\right)
$$

Where $\pi, 1, k, d$, @ and $\mu$ have been included in the constant coefficients A and B. 
According to equation (7), Kanevce and Oka [4] introduced the following expression to correct the hot-wire output voltage for the temperature drift:

$$
\mathrm{E}_{\text {corr }}=\mathrm{E}_{\mathrm{W}}\left(\frac{\mathrm{T}_{\mathrm{W}}-\mathrm{T}_{\mathrm{a}}}{\mathrm{T}_{\mathrm{w}}-\mathrm{T}_{\mathrm{a}, \mathrm{r}}}\right)^{0.5}
$$

$T_{a, r}$ is ambient reference temperature during sensor calibration and $T_{a}$ is ambient temperature during data acquisition where Ecorr is corrected voltage. For a hot wire probe with a finite length active wire element, the conductive heat transfer to prongs must be taken into account. In practice this is often achieved by the modifying equation [7] as:

$$
\frac{E_{w}^{2}}{R_{w}}=\left(A+B U^{n}\right)\left(T_{w}-T_{a}\right)
$$

The values of A, B and $\mathrm{n}$ can be determined by a suitable calibration procedure. It should be noted that the term $\left(T_{w}-T_{a}\right)$ and physical properties of fluid are dependent on the ambient temperature. In the previous related studies, the effect of term $\left(T_{w}-T_{a}\right)$ is considered only to compensate the ambient temperature variations [5]. In other word, the variations of physical properties of fluid and Nusselt number are ignored. So in this study, the variations of Nusselt number with the fluid temperature have been considered. The following equation for correction of output voltage E. has been proposed by the relations extended in Ref. [6].

$$
\mathrm{E}_{\text {corr }}=\mathrm{E}_{w}\left(\frac{\mathrm{T}_{\mathrm{W}}-\mathrm{T}_{\mathrm{a}, \mathrm{r}}}{\mathrm{T}_{\mathrm{W}}-\mathrm{T}_{\mathrm{a}}}\right)^{0.5(1 \pm \mathrm{m})}
$$

In Ref. [7], equation (10) is employed to correct the voltage of CTA output. Results showed that the required error correction factor $(\mathrm{m})$ depends on whether the fluid temperature decreases or increases with respect to the calibration temperature of the CTA.

The CT mode velocity and temperature sensitivities corresponding to equation (9) are:

$$
\begin{gathered}
S_{u}=\frac{\partial E_{w}}{\partial U}=\frac{n B U^{n-1}}{2}\left[\frac{R_{w}\left(T_{w}-T_{a}\right)}{A+B U^{n}}\right]^{0.5} \\
S_{\theta}=\frac{\partial E_{w}}{\partial \theta}=\frac{-1}{2}\left[\frac{R_{w}\left(A-B U^{n}\right)}{T_{w}-T_{a}}\right]^{0.5}
\end{gathered}
$$

Where $\theta$ is a small fluctuation in the fluid temperature. Equations (11) and (12) show that the value of $S_{u}$ increases and the value of $S_{\theta}$ decreases by increasing the value of $\left(T_{w}-T_{a}\right)$. $A$ high over-heat ratio $\left(R_{w} / R_{a}\right)$ is recommended for the measurement of velocity fluctuations [2]. In Ref. [7], it is stated that for an over-heat ratio of 1.4, the error incurred amounts to 
about $2.5 \%$ per degree Celsius temperature change. With the increase in the overheat ratio to 1.6, the error in CTA output is reduced to about $2 \%$ per degree Celsius temperature change.

The heat transfer process from a hot-wire sensor is usually expressed in a non-dimensional form where involve a relationship between the Nusselt number, the Reynolds number and the Prandtl number. The Nusselt number is usually assumed to be a function of Reynolds and Prandtl numbers and under most flow conditions, the Prandtl number is constant.

In hot-wire anemometry, the sizes of the sensing element are small, so that the Reynolds number of the flow is very low and the flow pattern over the sensor can be assumed to be symmetrical and quasi-steady. Due to the statement of the flow continuity, the mean free path of the particles is very much less than the diameter of the wire and conventional heat transfer theories are applicable [8]. Furthermore, the length of the sensor is much greater than its diameter. Hence, it may be assumed that the loss conduction through the ends is negligible and the relation for the heat transfer from an infinite cylinder can be applied. Kramers [9] has proposed the following equation based on heat-transfer experimental results for wires (with infinite length-to-diameter ratio), placed in air, water and oil:

$$
\mathrm{Nu}=0.42 \operatorname{Pr}^{0.2}+0.57 \operatorname{Pr}^{0.33} \operatorname{Re}^{0.5}
$$

He selected the film temperature $T_{f}=\left(T_{w}+T_{a}\right) / 2$ as the reference temperature for the fluid properties.

\section{Experimental procedure}

An air condition unit was used to carry out the experiments (Fig. 2). A laminar airflow was achieved by means of honeycombs network and screens. The air condition unit is powered by a small variable speed electric fan and four controllable heating elements provide a stable air temperature. The air flow velocity was measured by a pitot tube and a pressure transducer during the calibration and test. The output voltage from the hot-wire, pressure transducer output voltage, and the thermometer (NTC) output voltage are transferred to a computer, via an A/D card, having a 12 bit resolution and up to $100 \mathrm{kHz}$ frequency.

The sensing element in our case is a standard $5 \mu \mathrm{m}$ diameter tungsten wire that is heated by an electric current to a temperature of approximately $250{ }^{\circ} \mathrm{C}$. The active wire length is 1.25 $\mathrm{mm}$. For such probes, the convective heat transfer is about 85 percent of the total heat transfer from the heated-wire element [2].

Before measurements, the hot-wire sensor was calibrated in a wind tunnel and the response of the anemometer bridge voltage was also expanded as a least square fit with a $5^{\text {th }}$ order polynomial $\left(\mathrm{U}=\mathrm{C}_{0}+\mathrm{C}_{1} \mathrm{E}+\mathrm{C}_{2} \mathrm{E}^{2}+\mathrm{C}_{3} \mathrm{E}^{3}+\mathrm{C}_{4} \mathrm{E}^{4}+\mathrm{C}_{5} \mathrm{E}^{5}\right)$.

The experiments were carried out on a hot wire sensor operating at an over-heat ratio $\left(R_{w} / R_{a}\right)$ of 1.8 . The sensor, after calibration, was tested at different temperatures. The velocity range was $1-2 \mathrm{~m} / \mathrm{s}$, which corresponds to a Reynolds number of $0.18-0.35$, and the temperature range, was $17.5-40{ }^{\circ} \mathrm{C}$. 


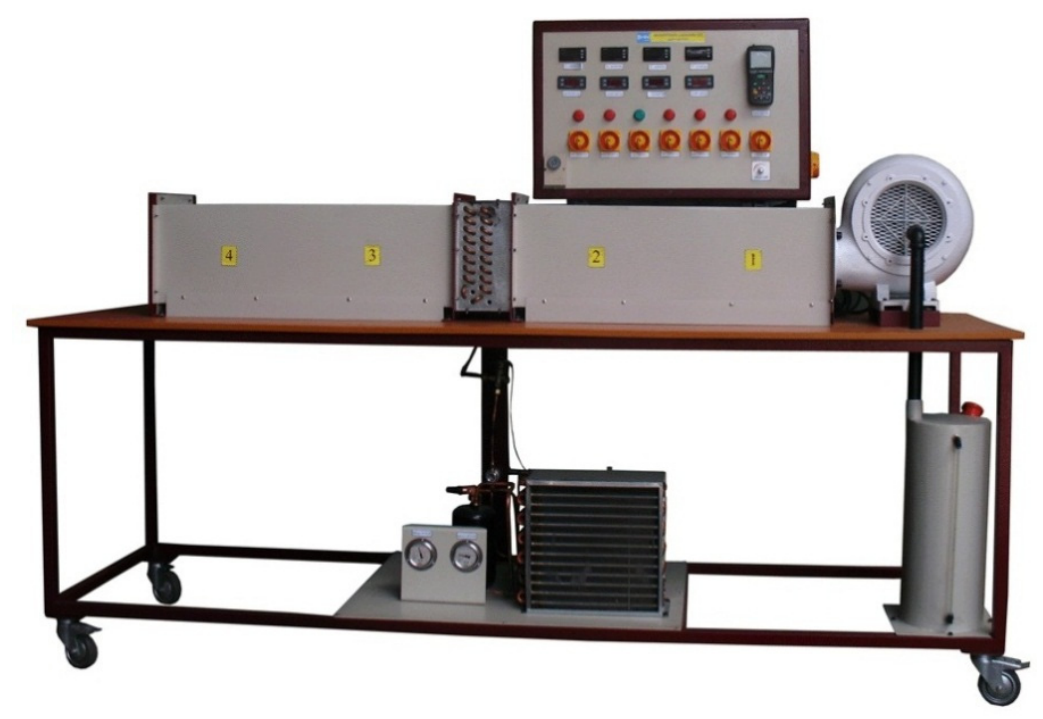

Figure 2. The laboratory air condition unit

\section{Results and discussions}

To examine the behavior of the hot wire sensor in different conditions and determine the temperature distribution along it, the general hot wire equation must be derived initially. By considering an incremental element of the hot wire, Fig.3, an energy balance can be performed where assume that there is the uniform temperature over its cross-section according to the equation (14).

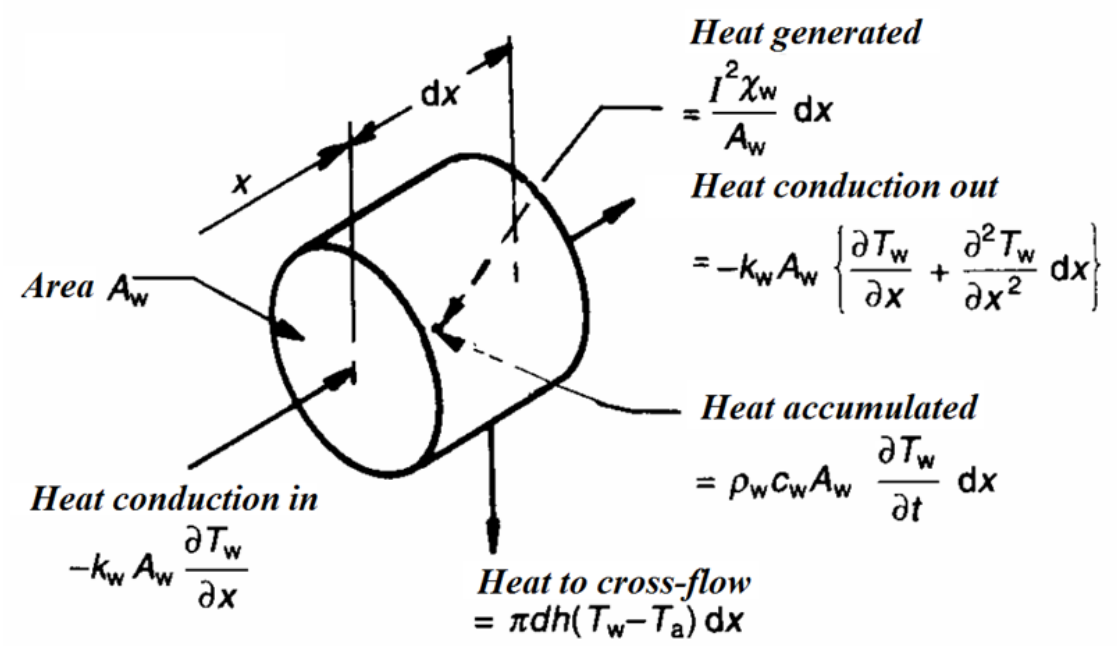

Figure 3. Heat balance for an incremental element [2]. 


$$
\frac{I^{2} \chi_{w}}{A_{w}}=\pi d h\left(T_{w}-T_{a}\right)-K_{w} A_{w} \frac{\partial^{2} T_{w}}{\partial x^{2}}+\pi d \sigma \varepsilon\left(T_{w}^{4}-T_{s}^{4}\right)+\rho_{w} c_{w} A_{w} \frac{\partial T_{w}}{\partial t}
$$

Where I is electrical current, $\chi_{\mathrm{w}}$ is the electrical resistant of the wire material at the local wire temperature, $T_{w}$, and $A_{w}$ is the cross-sectional area of wire where $h$ is the heat-transfer coefficient, $c_{w}$ is the specific heat of the wire material per unit mass, $k_{w}$ is the thermal conductivity of the wire material and $\mathrm{d}$ is the diameter of wire. With using the fourth-order Runge-Kutta method, this nonlinear secondary differential equation is solved in two conditions: with radiation term and without radiation term. Fig.4 shows the results for this step. As it is shown, the radiation term does not have any effect on the temperature distribution. The previous results achieved in Ref.[3] indicate that, the error due to radiation is in the range $0.1-0.01 \%$ and is quite negligible.

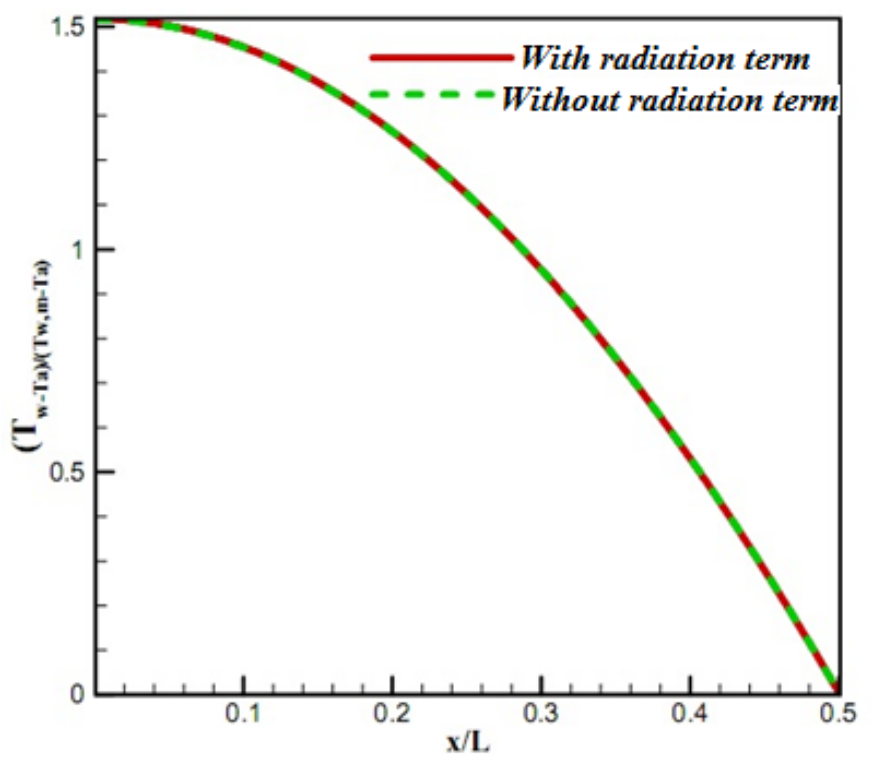

Figure 4. The solution of equation (14) with and without radiation term

Under steady conditions,

$$
\frac{\partial T_{w}}{\partial t}=0
$$

$\chi_{w}$ can be expressed as $\chi_{w}=\chi_{a}+\chi_{o} \alpha_{0}\left(T_{w}-T_{a}\right)$. Where $\chi_{a}$ and $\chi_{o}$ are the values of the resistivity at the ambient fluid temperature, $\mathrm{T}_{\mathrm{a}}$, and at $0^{\circ} \mathrm{C}$ and $\alpha_{\mathrm{o}}$ is temperature coefficient of resistivity at $0^{\circ} \mathrm{C}$. Thus, equation (14) can be rewritten as equation 15 [2]: 


$$
K_{w} A_{w} \frac{d^{2} T_{w}}{d x^{2}}+\left(\frac{I^{2} \chi_{o} \alpha_{o}}{A_{w}}-\pi d h\right)\left(T_{w}-T_{a}\right)+\left(\frac{I^{2} \chi_{a}}{A_{w}}\right)=0
$$

With assuming the ambient temperature is constant along the wire, this equation is of the following form (16):

$$
\frac{d^{2} T_{w}}{d x^{2}}+K_{1} T_{1}+K_{2}=0
$$

Where

$$
\mathrm{T}_{1}=\mathrm{T}_{\mathrm{w}}-\mathrm{T}_{\mathrm{a}}
$$

And

$$
\begin{gathered}
K_{1}=\left(\frac{I^{2} \chi_{o} \alpha_{o}}{A_{w}}-\pi d h\right) \\
K_{2}=\left(\frac{I^{2} \chi_{a}}{A_{w}}\right)
\end{gathered}
$$

The value of $K_{1}$ may be negative or positive. Therefore, the solution of equation (16) and temperature distribution along the wire are dependent on the value of $\mathrm{K}_{1}$. Equation (16) is solved in three states: $K_{1}<0, K_{1}=0, K_{1}>0$.

\subsection{State I: $\mathrm{K}_{1}<0$}

For more hot-wire applications, $K_{1}$ will be negative [2]. In Ref. [2], it is declared that in this state, the solution for a wire of length $\mathrm{L}$ will become:

$$
T_{w}=\frac{K_{2}}{\left|K_{1}\right|}\left[1-\frac{\cosh \left(\left|K_{1}\right|^{0.5} x\right)}{\cosh \left(\frac{\left|K_{1}\right|^{0.5} L}{2}\right)}\right]+T_{a}
$$

The mean wire temperature, $\mathrm{T}_{\mathrm{w}, \mathrm{m}}$ is obtained by integrating equation (17):

$$
T_{w, m}=\frac{1}{L} \int_{-L / 2}^{L / 2} T_{w}(x) d x
$$

Inserting equation (17) into equation (18) gives: 


$$
T_{w, m}=\frac{K_{2}}{\left|K_{1}\right|}\left[1-\frac{\tanh \left(\left|K_{1}\right|^{0.5} L / 2\right)}{\left|K_{1}\right|^{0.5} L / 2}\right]+T_{a}
$$

The non-dimensional steady state wire temperature distribution will be achieved such as equation (20) [2]:

$$
\frac{T_{w}-T_{a}}{T_{w, m}-T_{a}}=\frac{\left[\frac{L \times\left|K_{1}\right|^{0.5}}{2}\right]\left[\cosh \left(\frac{L \times\left|K_{1}\right|^{0.5}}{2}\right)-\cosh \left(x \times\left|K_{1}\right|^{0.5}\right)\right]}{\left[\frac{L \times\left|K_{1}\right|^{0.5}}{2}\right] \cosh \left(\frac{L \times\left|K_{1}\right|^{0.5}}{2}\right)-\sinh \left(\frac{L \times\left|K_{1}\right|^{0.5}}{2}\right)}
$$

Where $T_{a}$ is the ambient fluid temperature and $T_{w, m}$ is the mean wire temperature.

The convective and conductive heat transfer rate can be found from the flow conditions and the wire temperature distribution will earn according to the following equations:

$$
\begin{gathered}
\dot{Q}_{\text {cond }}=2 k_{w} A_{w}\left|\frac{d T_{w}}{d x}\right|_{x=l / 2} \\
\dot{Q}_{c o n v}=\pi d h L\left(T_{w, m}-T_{a}\right)
\end{gathered}
$$

To achieve a reasonable accuracy, the ratio of conductive heat transfer to convective heat transfer should be as low as possible.

$$
\frac{\dot{Q}_{\text {cond }}}{\dot{Q}_{\text {conv }}}=2 \frac{k_{w} A_{w}\left|K_{1}\right|^{0.5}}{\pi d L h} \times \frac{\tanh \left(0.5 L\left|K_{1}\right|^{0.5}\right)}{\left(1-\frac{2}{L\left|K_{1}\right|^{0.5}} \tanh \left(0.5 L\left|K_{1}\right|^{0.5}\right)\right)}
$$

According to equation (23), to reduce the effect of the conductive heat transfer rate, the wire should be as long as possible and the thermal conductive of the wire material should have a low value.

The temperature distribution in the form $\left(\mathrm{T}_{\mathrm{w}}-\mathrm{T}_{\mathrm{a}}\right) /\left(\mathrm{T}_{\mathrm{w}, \mathrm{m}}-\mathrm{T}_{\mathrm{a}}\right)$, is shown in Fig.5. It is shown that the uniformity of the temperature distribution along the wire increases for longer length wires. Also, the value of temperature in different parts of the wire approaches to mean temperature with escalating the length wire. 


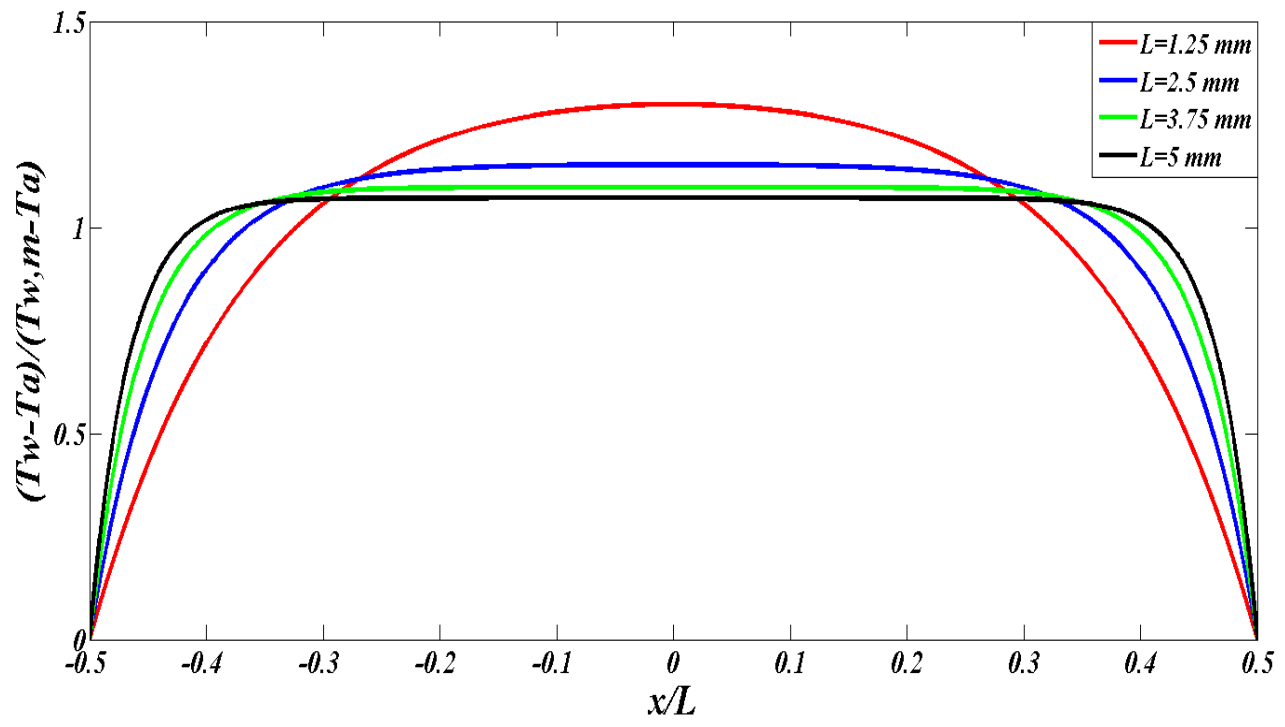

Figure 5. The temperature distribution along a hot wire for various values of $L\left(K_{1}<0\right)$.

The effect of wire length on the percent of conduction and convection heat transfer is shown in Fig. 6. (Diameter of wire is $5 \mu \mathrm{m}$ and the air velocity is equal to $20 \mathrm{~m} / \mathrm{s}$ ). As it is shown the conductive end losses reduces with increasing the wire length but it should be noted, the maximum value of tanh $\left(0.5 \mathrm{~L}\left|\mathrm{~K}_{1}\right|^{0.5}\right)$ is approximately 1 , so exceeding the wire length over $5.3 /\left|\mathrm{K}_{1}\right|^{0.5}$ will not cause a reduction in the conductive heat transfer rate.

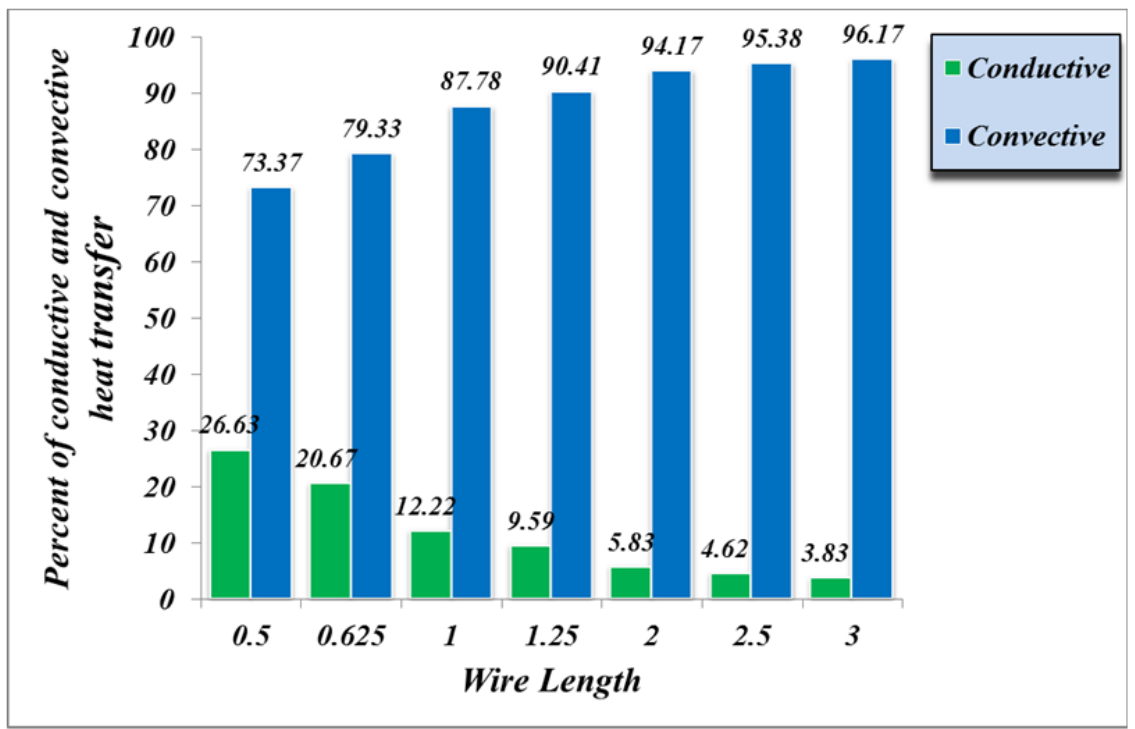

Figure 6. The percent of conduction and convection heat transfer for different wire length. 
For hot-wire anemometer applications it is usually advantageous to minimize the rate of conductive heat transfer rate relative to the forced convective heat transfer rate [2]. Fig.7 shows the effect of wire diameter on the non-dimensional temperature distribution. It is shown, the uniformity of temperature distribution decreases with increasing the wire diameter. This variation is due to increasing the wire diameter that will cause the conductive heat transfer rate to the two prongs to be increased as well.

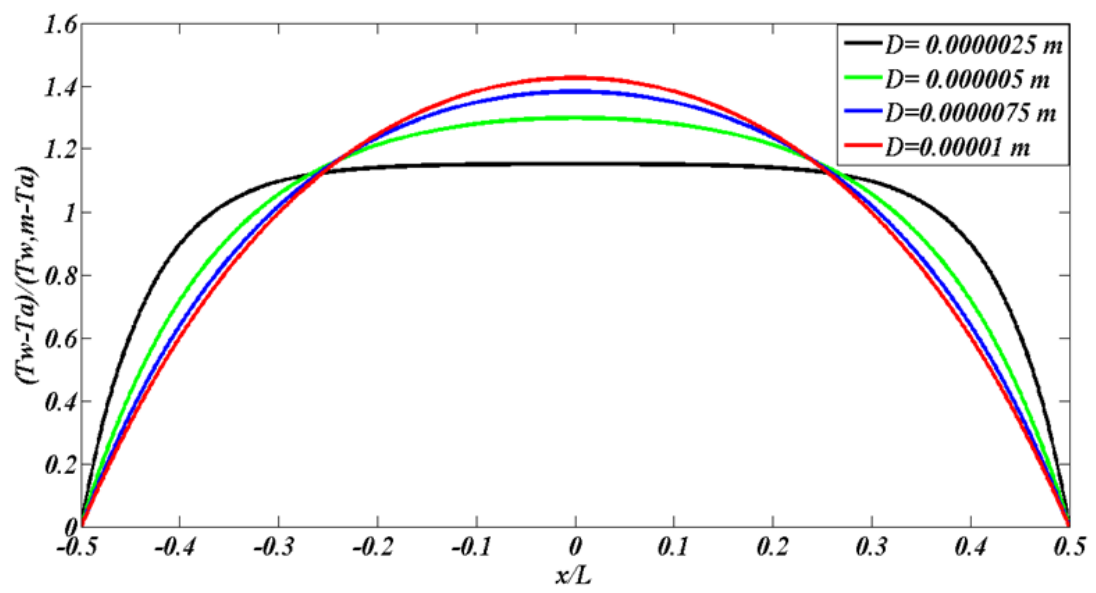

Figure 7. The temperature distribution along the hot wire for various values of $d(K 1<0)$.

Comparing between Figs. 6 and 7 shows that the wire diameter has the greater influence on the temperature distribution rather than the wire length.

\subsection{State II; $K_{1}=0$}

In this state, the temperature distribution equation is obtained as:

$$
T_{w}(x)=-\frac{1}{2} K_{2} L^{2}\left[\left(\frac{x}{L}\right)^{2}-\frac{1}{4}\right]+T_{a}
$$

According to equations (24) and (18), the mean wire temperature is determined as:

$$
T_{w, m}=\frac{1}{12} K_{2} L^{2}+T_{a}
$$

By using equations (24) and (25), the non-dimensional wire temperature distribution can be expressed as:

$$
\frac{T_{w}(x)-T_{a}}{T_{m}(x)-T_{a}}=-6\left[\left(\frac{x}{L}\right)^{2}-\frac{1}{4}\right]
$$


For this state, the non-dimensional temperature distribution is shown in Fig.8. It can be observed that the temperature distribution along the wire is independent of the wire length and for various values of $\mathrm{L}$, all temperature profiles are identical. Also, it can be observed from equation (26) that the non-dimensional temperature distribution does not depend on the wire diameter.

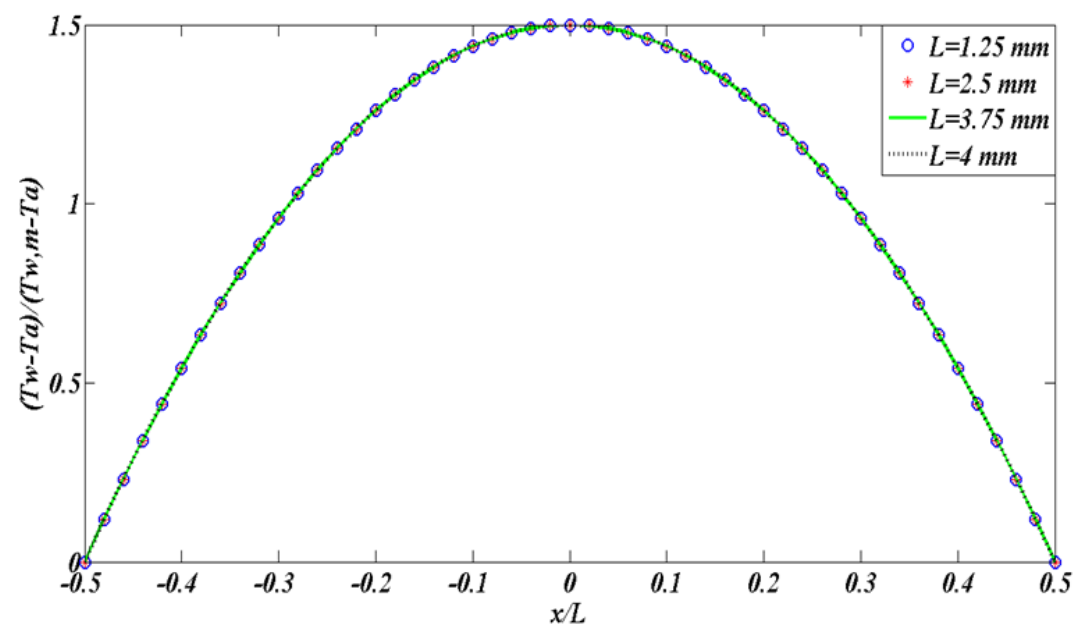

Figure 8. The temperature distribution along a hot wire for various values of $L(K 1=0)$.

Furthermore, the ratio of conductive heat transfer rate to the forced convective heat transfer rate can be expressed as:

$$
\frac{\dot{Q}_{\text {cond }}}{\dot{Q}_{\text {conv }}}=\frac{3}{2} \frac{k_{w} d}{h L}
$$

While it is shown, this ratio is directly proportional to the length and it will increase with inverse proportion to the wire diameter.

\subsection{State III; $\mathrm{K}_{1}>0$}

Using the mathematical analysis, it can be demonstrated that temperature distribution equation is:

$$
T_{w}=\frac{K_{2}}{K_{1}}\left[\frac{\cos \left(\left(K_{1}\right)^{0.5} x\right)}{\cos \left(\frac{\left(K_{1}\right)^{0.5} L}{2}\right)}-1\right]+T_{a}
$$


The mean wire temperature and the non-dimensional wire temperature distribution can be expressed as:

$$
\begin{aligned}
T_{w, m}=\frac{K_{2}}{K_{1}}\left[\frac{\tan \left(\left(K_{1}\right)^{0.5} L / 2\right)}{\left(K_{1}\right)^{0.5} L / 2}-1\right]+T_{a} \\
\frac{T_{w}-T_{a}}{T_{w, m}-T_{a}}=\frac{\left[\frac{L \times\left(K_{1}\right)^{0.5}}{2}\right]\left[\cos \left(x \times\left(K_{1}\right)^{0.5}\right)-\cos \left(\frac{L \times\left(K_{1}\right)^{0.5}}{2}\right)\right]}{\sin \left(\frac{L \times\left(K_{1}\right)^{0.5}}{2}\right)\left[\frac{L \times\left(K_{1}\right)^{0.5}}{2}\right] \cos \left(\frac{L \times\left|K_{1}\right|^{0.5}}{2}\right)}
\end{aligned}
$$

Fig.9 shows the non-dimensional temperature distribution $\left(\mathrm{K}_{1}>0\right)$. As it is shown, in this state some fluctuations appear in the temperature profiles. It can be demonstrated from equation (28) that, with approaching the wire length to $\pi /\left|\mathrm{k}_{1}\right| 0.5$, these fluctuations increases wherever the amplitude oscillatin decreases with growing the wire length.

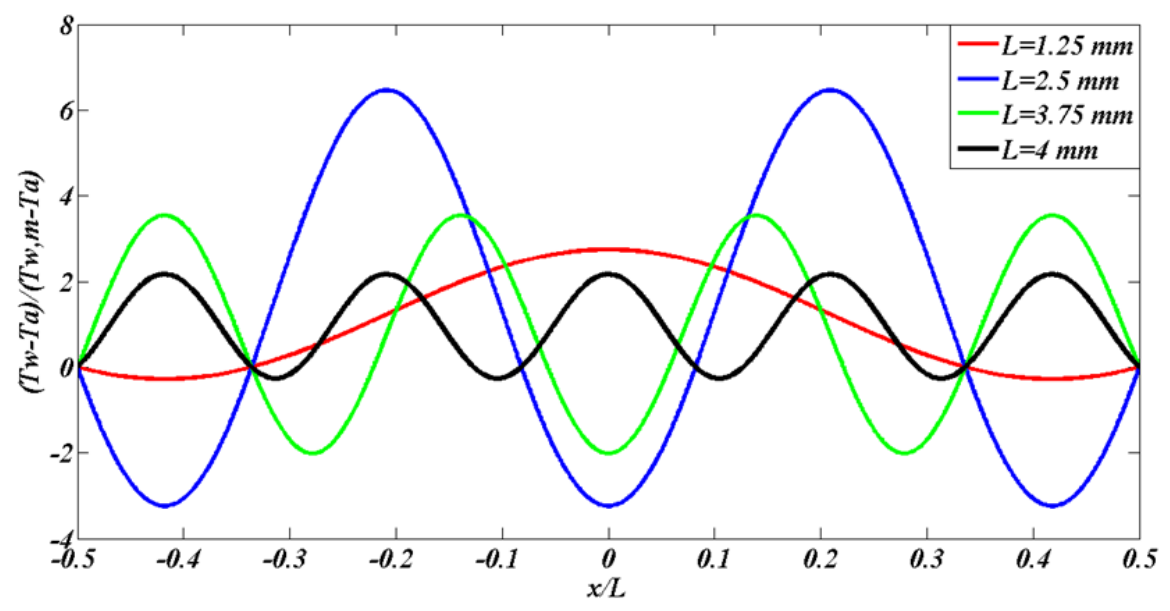

Figure 9. The temperature distribution along a hot wire for various values of $L(K 1>0)$.

It should be noted that the temperature profile is strongly dependent on the value of $\mathrm{K}_{1}$ which is relevant to the heat transfer coefficient (Nusselt number). With setting the value of $\mathrm{K}_{1}$ to zero, one could determine the critical Nusselt number as the following equation:

$$
N u_{c r i t i c a l}=\frac{I^{2} \chi_{o} \alpha_{o}}{A_{w} \pi k}
$$


In summary, the authors consider the temperature distribution along the hot-wire in the following cases:

Case I, $\mathrm{Nu}>\mathrm{Nu}$ critical: in this case, increasing the wire length and decreasing the wire diameter will cause the uniformity of temperature distribution to be increased considerably.

Case II, $\mathrm{Nu}=\mathrm{Nu}$ critical:in this case, the temperature distribution is independent of length and diameter of wire.

Case III, $\mathrm{Nu}<\mathrm{Nu}$ critical: here, temperature distribution is non-uniform and there are some fluctuations in temperature distribution.

According to equation (4), by knowing $E_{w}, R_{w}, T_{w}$ and $T_{a}$ in the anemometer, one can calculate the $\mathrm{Nu}$ number. The electrical resistance of the wire's material increases linearly with temperature, so that the resistance can be described as:

$$
R_{w}=R_{o}\left[1+\alpha_{o}\left(T_{w}-T_{o}\right)\right]
$$

Where $\mathrm{R}_{0}$ is the value of the resistance at a reference temperature $\mathrm{T}_{0}$ and $\alpha$ is the temperature coefficient of resistance. The recommended value for over-heat ratio is equal to 1.8 and the wire temperature of the chosen probe is then $249.22^{\circ} \mathrm{C}$.

In practical application, the hot-wire anemometer output is bridge voltage E (Fig. 1) whereas for determining the Nusselt number, the value of $E_{w}$ is required. For a balanced anemometer bridge, the relationship between $\mathrm{E}$ (bridge voltage) and $\mathrm{E}_{\mathrm{w}}$ (hot-wire sensor voltage) is:

$$
E_{w}=\frac{E}{R_{1}+R_{w}} R_{w}
$$

For comparison, the calculated Nusselt number by equation (4) that it is based on the fluid properties evaluated at the film temperature defined as the mean of the upstream flow temperature and temperature on the hot wire versus Reynolds number where based on the fluid properties evaluated at the film temperature is presented in Fig.10 with Kramer's experimental formula.

As it is shown, the data does not collapse to one curve and the deviation increases with increasing Reynolds number. Our results are lower than those given by Kramer's formula and the differences may be caused by the effect of conductive heat transfer to the prongs and three-dimensional effect encountered in experiments. In Ref. [2], it is stated that for a standard probe $(\mathrm{d}=5 \mu \mathrm{m}$ and $\mathrm{l}=1.25 \mathrm{~mm})$, the conductive heat transfer to the two prongs is about 15 percent of the total heat transfer from the heated-wire element. Although, the results in this study show that at the high velocity, the percentage of error between the predicted Nusselt number by Kramer's formula and the achieved Nusselt number in this study is $50 \%$. This result confirms that, there is a significant difference between the heat transfer process from finite length hot-wire sensor and infinite length one. 


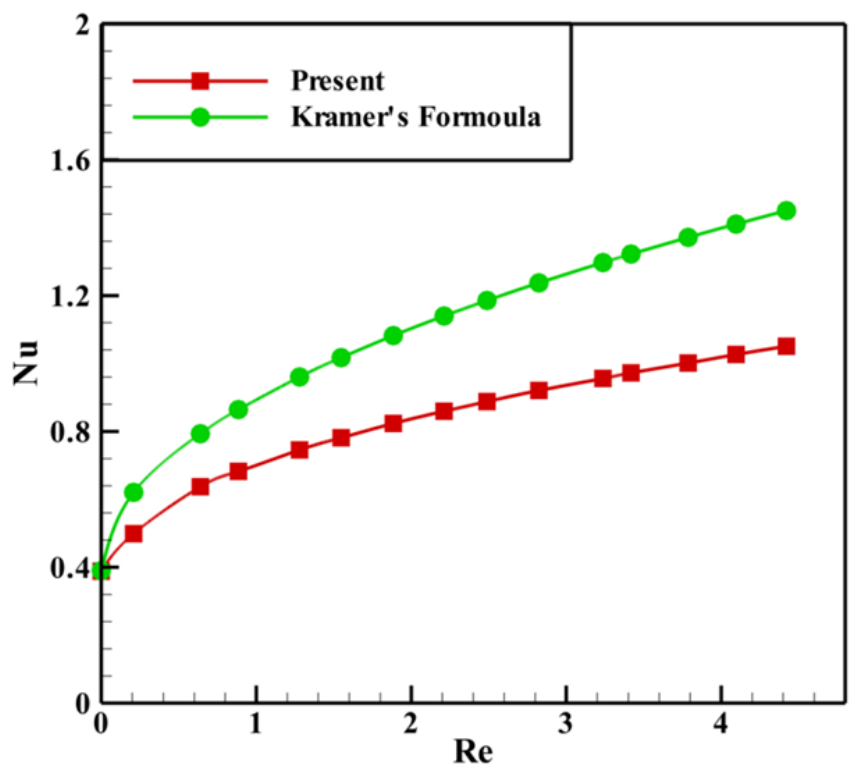

Figure 10. Heat transfer from a hot wire in a free stream flow.

In the next phase, the thermal response of the hot-wire anemometer relative to the velocity and also the air ambient temperature variation is investigated [11]. Figs. 11 and 12 show the variation of convection heat transfer coefficient (h) and Nusselt number versus Reynolds number at different ambient temperatures where fluid properties evaluated at the film temperature $\mathrm{T}_{\mathrm{f}}=\left(\mathrm{T}_{\mathrm{a}}+\mathrm{T}_{\mathrm{w}}\right) / 2$.

The achieved results indicate convection heat transfer coefficient and Nusselt number vary with variation of air flow temperature and as expected, both of them decrease with increasing the ambient temperature.

Different equations have been proposed to modify the Nusselt number. Lundström et al. [3] claim that it was necessary to evaluate the fluid properties at the air temperature and their results show that evaluating the properties at the film temperature is not enough to achieve a temperature independent calibration law. Collis and Williams [10] realized, using the film reference temperature, that it was necessary to include a temperature loading factor in the Nusselt number King's law according to the following equation;

$$
N u\left(\frac{T_{f}}{T_{a}}\right)^{-0.17}=A+B R e^{0.45}
$$

Nusselt number (hd/k) includes both the heat-transfer coefficient and the thermal conductivity of the fluid and these parameters are dependent on the ambient temperature. The temperature role on $\mathrm{k}$ can be expressed as: 


$$
\frac{k}{k_{r}}=\left(\frac{T}{T_{r}}\right)^{a}
$$

$\mathrm{T}$ and $\mathrm{T}_{\mathrm{r}}$ are in absolute temperature but the variation of $\mathrm{h}$ with ambient temperature is unknown.

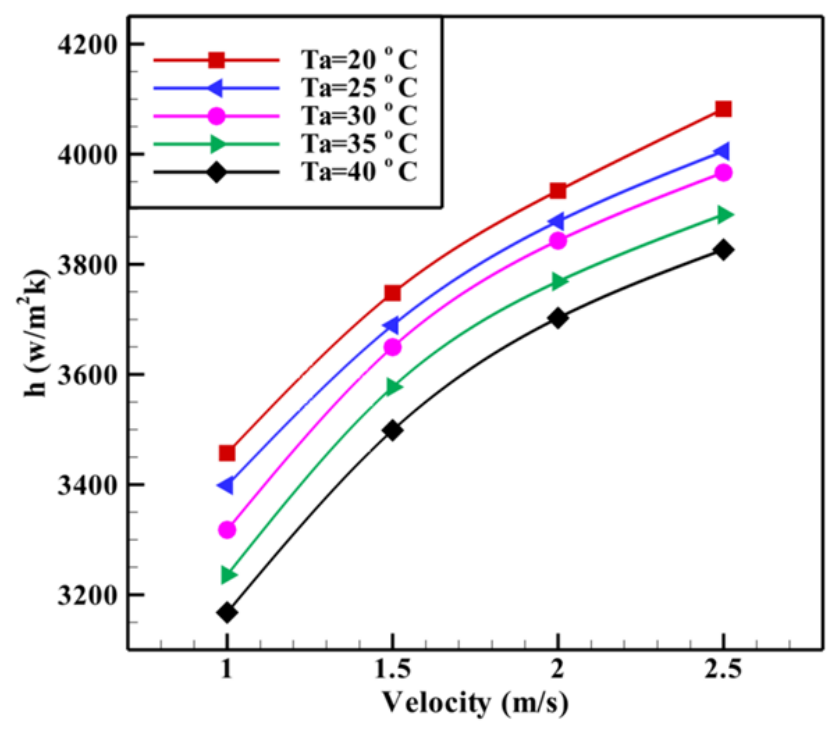

Figure 11. Variations of heat-transfer coefficient Vs. velocity at different ambient temperatures. [11]

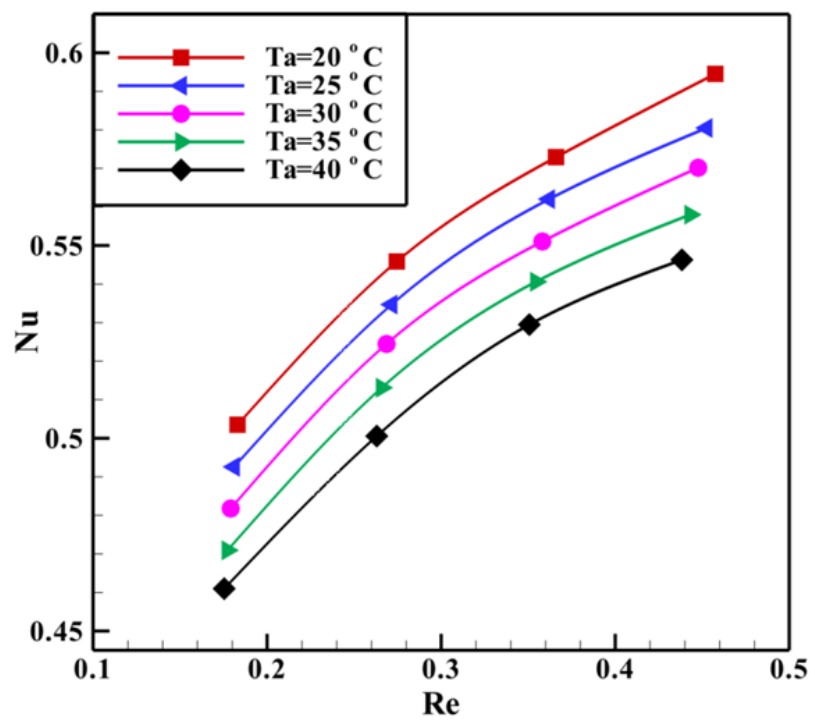

Figure 12. Variations of Nusselt number Vs. Re at different ambient temperatures. [11] 
However, the fundamental mechanism for variation of Nusselt number is not known yet but it can be compensated empirically by introducing the modified Nusselt number according to the following equation [11]:

$$
N u_{c o r r}=N u\left(\frac{T_{a}}{T_{a, r}}\right)
$$

Where temperatures are in absolute temperature and $T_{a, r}$ is the reference temperature at which the sensor calibration is performed. When the correction is applied to the data in Fig. 12, the data collapse approximately to a single curve as shown in Fig.13.

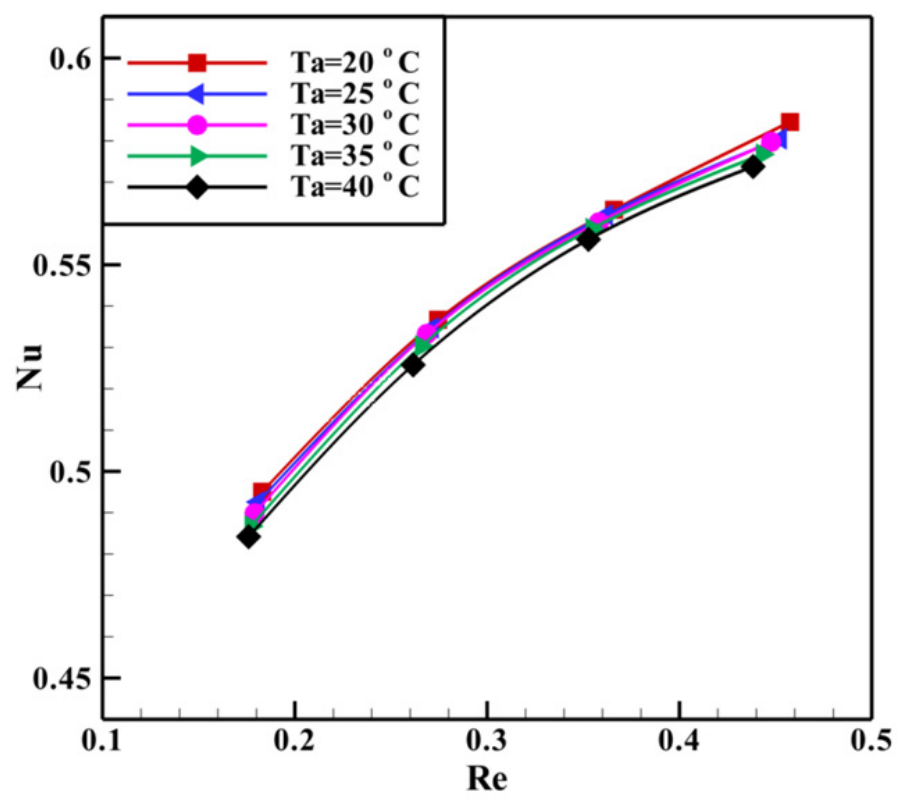

Figure 13. The achieved Nusselt number Vs. Re by employing equation (36) [11].

Fig. 14 presents the response of the CTA on wind speed approximately equal to 1 and $2 \mathrm{~m} / \mathrm{s}$ at various temperatures. The temperature varies between 22.5 and $37.5^{\circ} \mathrm{C}$. As it is shown, the bridge voltage decreases as the higher ambient temperature.

Calibration equations do not include ambient temperature variations, so a correction procedure should be applied. There are three main practical ways [2]:

- $\quad$ Automatic compensation: Use a temperature sensor in the Wheatstone bridge.

- Manual adjustment: Manual adjustment can be made by changing the value of the resistant, $\mathrm{R}_{\mathrm{w}}$, to compensate the changes in $\mathrm{T}_{\mathrm{a}}$. 
- Analytical correction: Measure the flow temperature separately and compensate using the heat transfer equation.

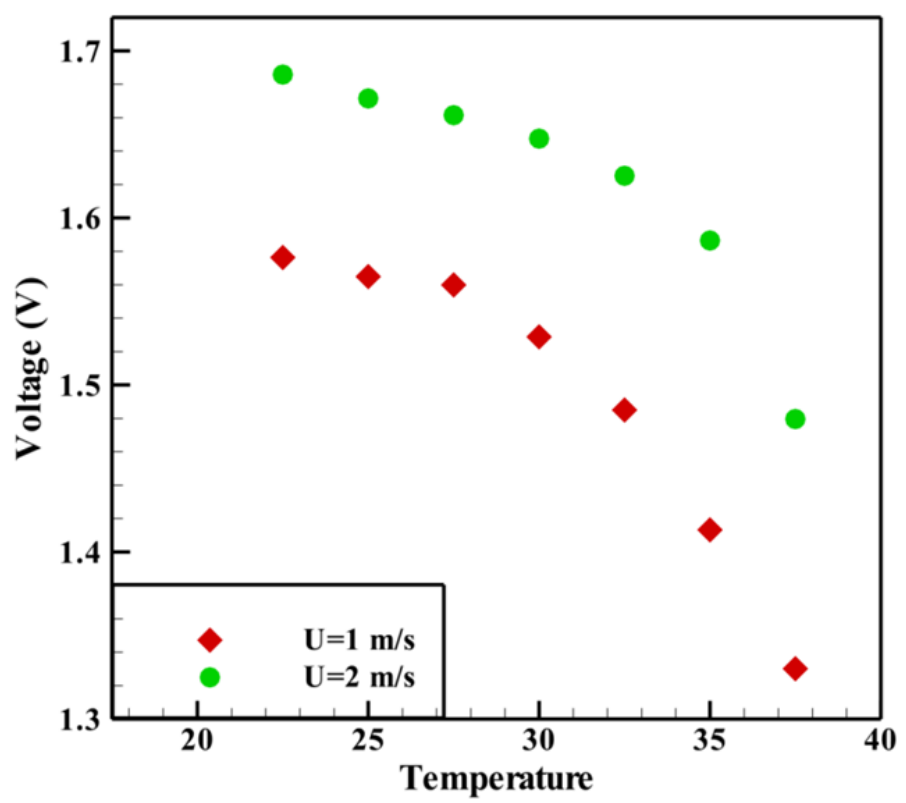

Figure 14. Response of CTA at various ambient temperatures. [11]

In this research, the voltage error due to changes in the ambient temperature is corrected using equation (10) and (37):

$$
\mathrm{E}_{\mathrm{W}}=\mathrm{E}\left(\frac{\mathrm{T}_{\mathrm{w}}-\mathrm{T}_{\mathrm{a}}}{\mathrm{T}_{\mathrm{w}}-\mathrm{T}_{\mathrm{a}, \mathrm{r}}}\right)^{0.5} \times\left(\frac{\mathrm{T}_{\mathrm{a}}}{\mathrm{T}_{\mathrm{a}, \mathrm{r}}}\right)^{0.5}
$$

Equation (10) only considers the effect of ambient temperature variation but equation (37) regards the effect of Nusselt variation as well the ambient temperature variation.

The percentage error is presented in Fig.15 as a function of flow temperature. The other parameters are reference temperature, $\mathrm{Ta}, \mathrm{r}=25^{\circ} \mathrm{C}$, average sensor temperature, $\mathrm{Tw}=249.22$ ${ }^{\circ} \mathrm{C}$ and flow velocity, $\mathrm{U}=1.5 \mathrm{~m} / \mathrm{s}$.

It can be seen that the achieved results from equation (37) are more reasonable. It should be noted that by increasing the air temperature, the fluid properties will be changed and these changes have to be taken into consideration. This factor is considered in equation (37) so that at high air temperature it can compensate the ambient temperature variations adequately. 


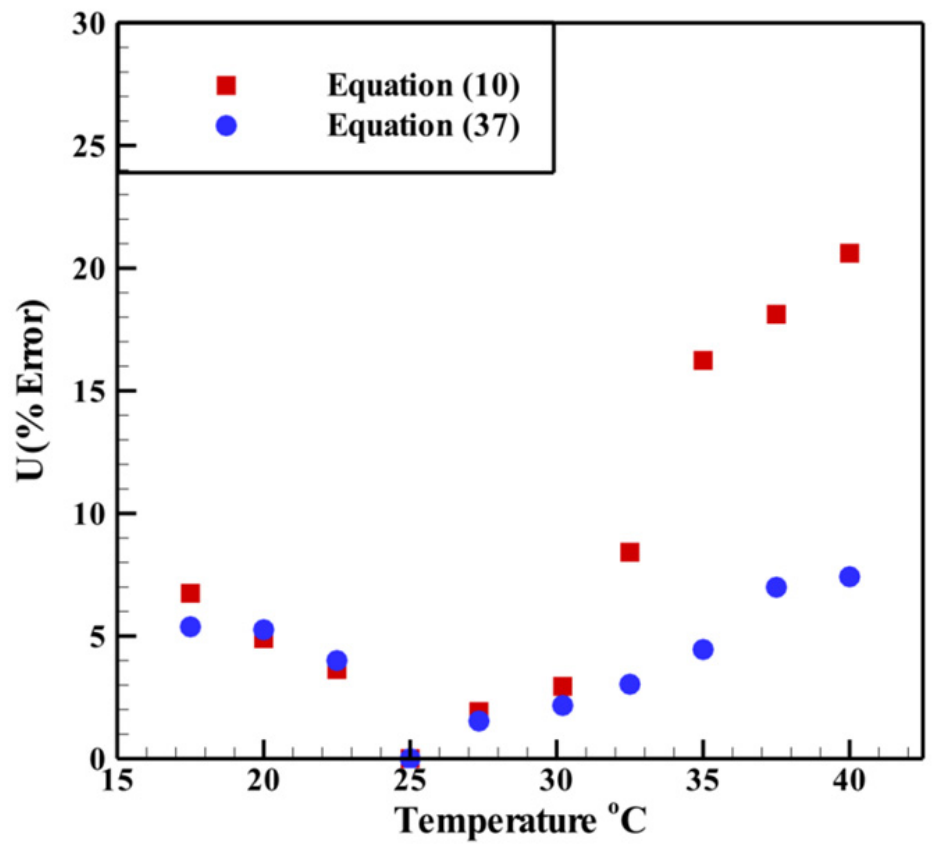

Figure 15. Error in the measurement of flow velocity for the hot wire sensor [11]

\section{Conclusion}

The analytical solutions for heat transfer equation of hotwire indicate that the temperature distribution along a hot-wire sensor is dependent on the critical Nusselt number. $\mathrm{Nu}<\mathrm{Nu}$ critical leads to increasing the wire length and decreasing the wire diameter which will cause the uniformity of temperature distribution to be increased considerably. For $\mathrm{Nu}=\mathrm{Nu}$ critical, wire length and diameter don't have any effect on the temperature distribution. If $\mathrm{Nu}>\mathrm{Nu}$ critical, some fluctuations will appear in the temperature profiles.

The results from experimental investigation show that the values of both the air temperature and Nusselt number have influence on the output voltage of the CTA. In this study, two ways have been employed to compensate the ambient temperature changes. In the first case, the effect of ambient temperature variation is only considered but in the second case, the effect of Nusselt variation is also regarded. At low temperature variation, the accuracy of two methods is almost the same whereas by increasing the air temperature, the second method which consider the changes in fluid properties, provide more accurate results in compare with the first method. 


\section{Appendix}

Aw Surface area of sensor, $\mathrm{m}^{2}$

$\mathrm{Cw} \quad$ Specific heat of the wire material per unit mass, $\mathrm{J} / \mathrm{Kg}$. K

D Wire diameter, $\mathrm{m}$

E Bridge voltage, $\mathrm{V}$

Ecorr $\quad$ Corrected voltage, $\mathrm{V}$

Ew Hot-wire sensor voltage, $\mathrm{V}$

$\mathrm{H} \quad$ heat-transfer coefficient, $\mathrm{W} / \mathrm{m}^{2} . \mathrm{K}$

I Electrical current passing through the sensor, A

K Thermal conductivity of the fluid, W/m. K

$\mathrm{k}_{\mathrm{w}} \quad$ Thermal conductivity of the wire material, W/m. K

L Wire length, $\mathrm{m}$

M Temperature loading factor used in equation (10)

$\mathrm{N} \quad$ Constant used in equation (7)

$\mathrm{Nu} \quad$ Nusselt Number, hd/k

Pr Prandtl number, $\mu \mathrm{Cp} / \mathrm{K}$

$\dot{Q}_{\text {elec }} \quad$ Electrical power dissipation, W

Re Reynolds number, ud/v

$R_{w} \quad$ Sensor resistance

$\mathrm{T}_{\mathrm{a}} \quad$ Ambient temperature during data acquisition, $\mathrm{K}$

$\mathrm{T}_{\mathrm{a}, \mathrm{r}} \quad$ Ambient reference temperature during sensor calibration, $\mathrm{K}$ 


$\begin{array}{ll}\mathrm{T}_{\mathrm{w}} & \text { Temperature of hot-wire sensor, } \mathrm{K} \\ \mathrm{T}_{\mathrm{w}, \mathrm{m}} & \text { Mean wire temperature, } \mathrm{K} \\ \mathrm{U} & \text { Instantaneous velocity, } \mathrm{m} / \mathrm{s} \\ \text { Ao } & \text { Temperature coefficient of resistivity at } 0^{\circ} \mathrm{C} \\ \mathrm{E} & \text { Emissivity of the sensor } \\ \Sigma & \text { Stefan-Boltzmann constant } \\ \chi_{0} & \text { Values of resistivity at } 0^{\circ} \mathrm{C} \\ \chi_{a} & \text { Values of resistivity at the ambient fluid temperature } \\ \mathrm{M} & \text { Dynamic viscosity, N.s } / \mathrm{m}^{2}\end{array}$

\section{Author details}

Mojtaba Dehghan Manshadi and Mohammad Kazemi Esfeh

Malekashtar University of Technology, Iran

University of Yazd, Yazd, Iran

\section{References}

[1] Manshadi M. D. (2011). “The Importance of Turbulence in Assessment of Wind Tunnel Flow Quality", Book chapter No. 12, Wind Tunnels and Experimental Fluid Dynamics Research, Edited by Jorge Colman Lerner and Ulfilas Boldes, Intech publisher.

[2] Bruun H H. Hot-wire Anemometry, Principles and Signal Analysis. Oxford University Press; 1995.

[3] LundstrÖm H, Sandberg M, Mosfegh B. Temperature dependence of convective heat transfer from fine wires in air: A comprehensive experimental investigation with application to temperature compensation in hot-wire anemometry. Experimental Thermal and Fluid Science 2007; 32: 649-657.

[4] Kanevce G, Oka S. Correcting hot-wire readings for influence of fluid temperature variations 1973. DISA Info, No. 15, 21-24.

[5] Benjamin SF, Roberts CA. Measuring flow velocity at elevated temperature with a hot wire anemometer calibrated in cold flow. Heat and Mass Transfer 2002; 45: 703-706.

[6] Improved temperature correction in stream Ware®. DANTEC DYNAMICS. Technical Note of dynamics, Publication No.TN049909, P2, 2002. 
[7] Ardakani MA, Farhani F. Experimental study on response of hot wire and cylindrical hot film anemometers operating under varying fluid temperatures. Flow Measurement and Instrumentation 2009; 20: 174_179.

[8] Suminska OA. Application of a constant temperature anemometer for balloon-borne stratospheric turbulence soundings. MSc thesis. University of Rostock; 2008.

[9] Kramers H. Heat transfer from spheres to flowing media. Physica 1946;12:61-80.

[10] Collis DC, Williams MJ. Two-dimensional convection from heated wires at low Reynolds numbers. J. Fluid Mech 1959; 6:357-384.

[11] Dehghan Manshaid M, Kazemi Esfeh M. A new approach about heat transfer of hotwire anemometer. Accepted to publishing in the Applied Mechanics and Materials Journal, 2012. 